http://dx.doi.org/10.4314/gjl.v7i1.1

\title{
COORDINATION IN NKAMI
}

\author{
Rogers Krobea Asante
}

\begin{abstract}
In this paper I comprehensively discuss the syntactic phenomenon of coordination in Nkami, an endangered, less known Guang (Kwa, NigerCongo) language of Ghana, based on synchronic natural data. I discuss issues including Nkami's coordination strategies, its number and types of coordinators, morpho-phonological make-up and distributional abilities of the coordinators, allowable types of syntactic structures for coordination, and the semantic effect(s) of the coordinators on coordinate structures. In addition, some constraints governing Nkami's coordination, and the multi-functionality and source concepts of the coordinators are also discussed. Among other things, it is observed that Nkami employs both syndetic (overt) and asyndetic (covert) strategies for coordination though the latter is highly restricted, occurring chiefly in narratives and pithy sayings. Nkami employs a Serial Adjective Construction (or an asyndetic) strategy when modifiers (adjectives) in a sentence modify the same referent, while a Coordinate Adjective Construction (or a syndetic) strategy is used when the modifiers qualify different referents within the same sentence. Like regional languages, Nkami has clearly distinct and-coordinators for phrasal and clausal coordination. Lastly, almost all the coordinators in Nkami are multi-functional, and are diachronically derivable from more lexical or less grammatical concepts.
\end{abstract}

Keywords: Coordination, coordination strategies, linguistic properties of coordinators, multi-functionality and grammaticalization of coordinators, semantics of coordination 


\section{Introduction ${ }^{1}$}

The purpose of this paper is to offer an expository account of phrasal and clausal coordination in Nkami, an endangered Guang (Kwa, Niger-Congo) language of Ghana. Coordination is one of the commonest morphosyntactic means of joining identical words (phrases), clauses and sentences together (cf. Dik 1968, Welmers 1973, Sanders 1977, Payne 1985, Mithun 1988, Stassen 2000, Wälchli 2003, Haspelmath 2004, 2007). Haspelmath $(2004,2007: 1)$ characterizes coordination as "syntactic constructions in which two or more units of the same type are combined into a larger unit and still have the same semantic relations with other surrounding elements." The set of possible units that may be coordinated (called coordinands) ${ }^{2}$ include words, phrases, subordinate clauses, full clauses or sentences, as the following exemplify accordingly:
a. I sing and/or dance every day.
b. $\quad$ My father and my grandmother are rich.
c. I realized that she was sick but she didn't open up.
d. My father schooled at Tongji University but his wife went to University of Ghana.

Usually, the individual clauses linked together in coordination are grammatically independent; hence, they do not exhibit overt signs of grammatical dependency. As a result, the coordinands of clausal coordination are normally considered as the least grammatically integrated compared to other types of multi-verb constructions and clause combinations such as serial verbs, relative clause, complement clause, and adverbial clause constructions. Two or more clauses (sentences) may be eligible for coordination if they share the same mood, (i.e. are imperatives, interrogatives or declaratives), and/or perform an identical function (cf. Dik 1968, Haspelmath 2004, 2007). Coordination is also often examined in terms of the number, types and position of connective devices (called coordinators) a language possesses. English, like most European languages, for instance, has only one and-coordinator, which occurs in medial position, for both phrasal and clausal conjunctive coordination, as (2a) and (2b)

\footnotetext{
${ }^{1}$ This paper is a thoroughly modified version of an aspect of a doctoral dissertation on the grammar of Nkami. The database for this study comprises spontaneous spoken and elicited texts gathered from about a hundred speakers of diverse backgrounds in a period of one year in Amankwa, the language community. The annotation and verification of data were carried out in collaboration with a team of two adult Nkami speakers, Kwadwo Akuamoah and Kwaku Ketewa, and several other language consultants. I wish to thank the Endangered Language Documentation Project (ELDP) for sponsoring the Nkami Documentation Project that has culminated into this paper. I also wish to thank the Editor and anonymous reviewers for their helpful comments and suggestions. As usual, for the people of Nkami, this work is yours.

${ }^{2}$ The terminologies used in this paper are mainly from Haspelmath $(2004,2007)$.
} 
illustrate accordingly.

(2) a. Mary and John visited their grandma.

b. Mary visited her grandma and John visited his grandpa.

However, many languages of Africa (cf. Welmers 1973, Abdoulaye 2004, Lefebvre 2004) have distinct coordinators for phrasal and clausal coordinative conjunction, as the Ewe data in (3) illustrate (Dzameshi 1988/1989: 73-74).
$\begin{array}{lllll}\text { a. Yao } & \text { kple } & \text { Abla wo } & \text { dzo } \\ \text { Yao and } & \text { Abla they leave }\end{array}$
'Yao and Abla have left.'
b. Eyram mlo anyi eye Selom no anyi de aba dzi Eyram lie ground and Selom sit ground on bed top 'Eyram lay down and Selom sat on the bed.'

Thus, unlike English, Ewe employs two distinct coordinators, kple and eye, for phrasal and clausal conjunctive coordination respectively. For all the examples seen so far, there is only one coordinator that conjoins the coordinands together. These languages are referred to as monosyndetic languages (cf. Haspelmath 2004, 2007). However, there are cases in some other languages where a coordinator associates with each coordinand. For instance, in order for phrasal conjunction to be acceptable in Upper Kuskokwim Athabaskan, each of the coordinands (i.e. maladija 'tent', jamena 'stove', denk'a 'gun' and łeka mama' 'dog food') is required to be associated with the coordinator 'ił , as (4) shows (Kibrik 2004: 539).

\begin{tabular}{llllllll} 
Maladija & 'ił & jamena & 'il & \multicolumn{2}{l}{ denk'a 'ił } & łeka & mama' 'ił \\
tent & with & stove & with & gun with & dog & food with \\
'a tent, a stove & a gun & and dog food'
\end{tabular}

Languages like Upper Kuskokwim Athabaskan that employ this latter strategy are called polysyndetic languages (cf. Haspelmath 2004, 2007).

Moreover, apart from these examples of syndeton, there also exists cases of asyndectic (zero) coordination where the coordinands are merely juxtaposed without any overt coordinator(s), as (5) illustrates with data from Vietnamese (cf. Watson 1966: 170, Payne 1985: 26, Payne 1997: 338).

(5)a. NP coordination

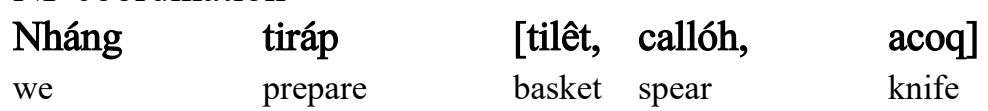

'We prepare baskets, spears and knives.' 
b. Clausal coordination

$\begin{array}{lllll}\text { do } & \text { [chô tôq cayâq, } & \text { chô tôq } & \text { apây] } \\ \text { she } & \text { return to } & \text { husband } & \text { return to } & \text { grandmother }\end{array}$

'She returns to (her) husband and returns to (her) grandmother.'

Thus, Vietnamese extensively employs asyndetic coordination strategy for both phrasal and clausal coordination, as (5a) and (5b) exemplify.

Further, among other things, coordination may also be looked at in terms of the morpho-phonological and syntactic properties of the coordinators, allowable types of syntactic structures for coordination, multi-functionality and source concepts of coordinators, semantic effect(s) of coordinators on coordinate structures, and the rules governing ellipsis in coordination (cf. Ross 1967, Jacops and Rosenbaum 1968, Sanders 1977, Schachter 1977, Payne 1985, Wälchli 2003, Haspelmath 2007). Consequently, in order to provide a good account of coordination in Nkami, we rubricise the rest of our discussion into six sections based on the following parameters: Section 2 - coordination strategies, Section 3 - linguistic properties of the coordinators, Section 4 -allowable syntactic structures for coordination (phrasal versus clausal coordination), Section 5 semantics and diachronic lines of the coordinators, Section 6 - coordination and elliptical rules, Section 7 - summary and conclusion.

Among others, it will be shown that Nkami employs both syndetic (overt) and asyndetic (covert) strategies for coordination though the former is highly limited, surfacing mainly in pithy sayings and narratives. Secondly, just like the majority of the world's languages (cf. Payne 1985, Mithun 1988, Stassen 2000, Haspelmath 2004, 2007), Nkami employs the monosyndetic NP-coordination strategy by way of a medial connective. Moreover, whereas Nkami employs a Serial Adjective Construction (or an asyndetic) strategy when modifiers (adjectives) in a sentence modify the same referent, a Coordinate Adjective Construction (or a syndetic) strategy is used when the modifiers qualify different referents within the same sentence. The paper also shows four distinguishing features between the two multi-verb construction types, (asyndetic) coordination and (linking) SVC, in Nkami with regards to the following parameters: intonation break, negation marking, subject marking, and the number of allowable adverbials belonging to the same sub-semantic type in a sentence. Further, like other languages of Africa (cf. Welmers 1973, Abdoulaye 2004, Lefebvre 2004), Nkami has distinct coordinators, na and $\mathrm{nr}$, for phrasal and clausal conjunctive coordination respectively. Moreover, Nkami shows evidence of the three major semantic types of coordination (Haspelmath 20004, 2007): conjunction (conjunctive coordination or 'and' coordination), disjunction (disjunctive coordination or 'or' coordination), and adversative coordination ('but' coordination). Other sub-semantic domains such as animacy, conceptual closeness or naturalness, emphasis and inclusion (cf. Mithun 1988, Stassen 2000, Wälchli 2003, Haspelmath 2007) do not play any significant role(s) in coordination in Nkami. Lastly, almost all the coordinators in Nkami are multifunctional, and are traceable to more lexical or less grammatical concepts. 


\section{Coordination Strategies in Nkami ${ }^{3}$}

Nkami speakers employ the two main types of coordination strategies to connect structures in coordination: syndetic coordination, where an overt coordinator is employed to join the coordinands in coordination, and asyndetic coordination, where the coordinands are merely juxtaposed. Looking at syndetic coordination first, like all other languages, Nkami has a closed set of coordinators. They include the conjunctive coordinators, na and $\mathrm{nr}$ 'and', the adversative coordinators, mossu and mo 'but', and the disjunctive coordinator bec 'or'. In example (6) are coordinate sentences showing the use of the coordinators in contexts. ${ }^{4}$

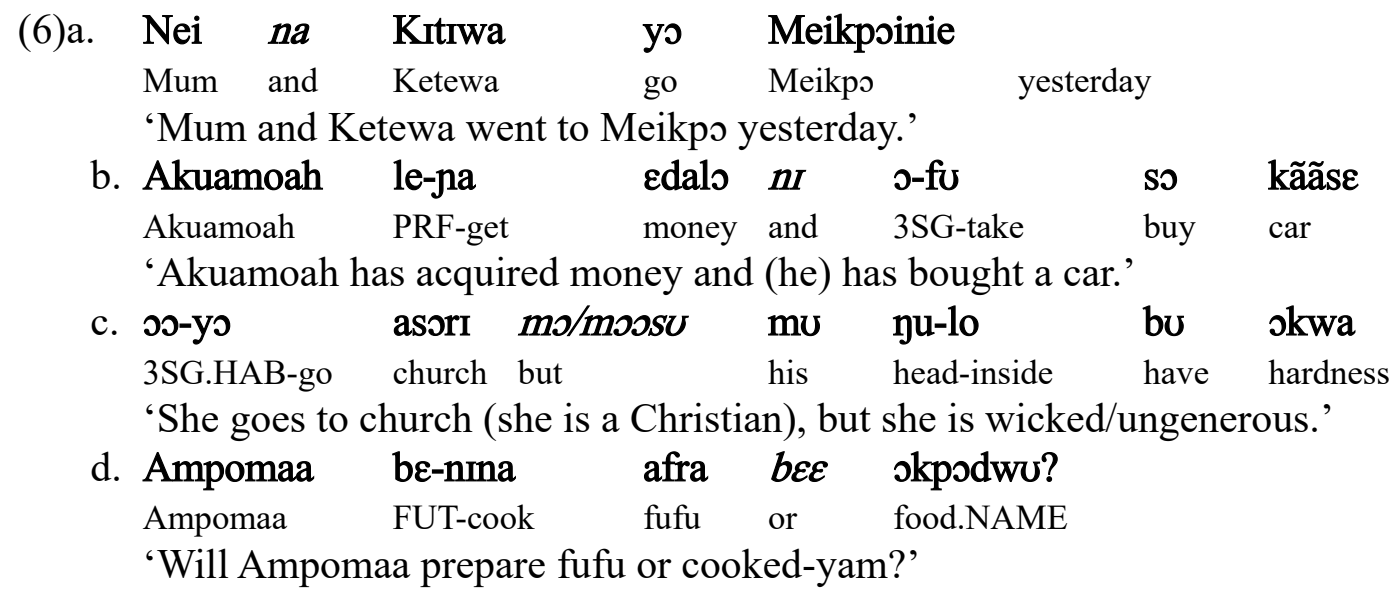

In the data above, na conjoins the NPs, nei 'mum' and Kitrwa, in (6a), nI conjoins the two clauses (sentences), Akuamoah lena edalo 'Akuamoah has acquired money' and ofo

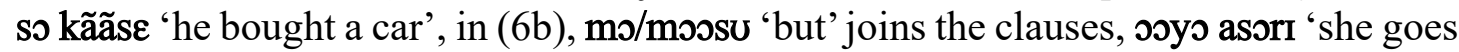
to church' and mu yulo bu okwa 'she is wicked/ungenerous', in (6c), and beع 'or' connects the two clauses, Ampomaa benina afra 'Ampomaa will prepare fufu' and Ampomaa benma skpodwo 'Ampomaa will prepare cooked-yam', in (6d). Notice that

\footnotetext{
${ }^{3}$ Nkami bears most of the linguistic features of regional languages. It is a tongue root (ATR) harmonic language, it exhibits both lexical and grammatical functions of tone, it is an SVO language, it portrays prototypical features of serial verb constructions (SVCs), its morphological processes are prominently expressed through affixation, compounding and reduplication, and its verbal properties are represented by prefixes and verbal particles (cf. Asante 2016a, b).

${ }^{4}$ I use the following abbreviations: $1=$ first person; $2=$ second person; $3=$ third person; $\mathrm{CDP}=$ correlative disjunctive particle; $\mathrm{COMP}=$ complementizer COND = conditional marker; $\mathrm{CONJ}=$ conjunction; $\mathrm{DEF}$ $=$ definite article DEM = demonstrative FUT = future $\mathrm{HAB}=$ habitual $; \mathrm{NEG}=$ negation; $\mathrm{OBJ}=$ object; $\mathrm{PL}=$ plural $; \mathrm{POSS}=$ possessive $; \mathrm{PRF}=$ perfect $; \mathrm{PROG}=$ progressive $; \mathrm{PST}=$ past $; \mathrm{PURP}=$ purposive marker; $\mathrm{REL}=$ relative marker; $\mathrm{SG}=$ singular; $\mathrm{SVC}=$ serial verb construction.
} 
Nkami is a monosyndetic language because in all the coordinate structures above, the coordinator occurs only once. It is also largely medial syndetic because the coordinators typically occur in between the coordinands (see Section 4 for more details). On the other hand, in addition to the above-mentioned coordinators, there also exists the correlative disjunctive particle (CDP), oow... oow 'whether... or', which may be considered as a bisyndetic coordinator, as (7) illustrates.

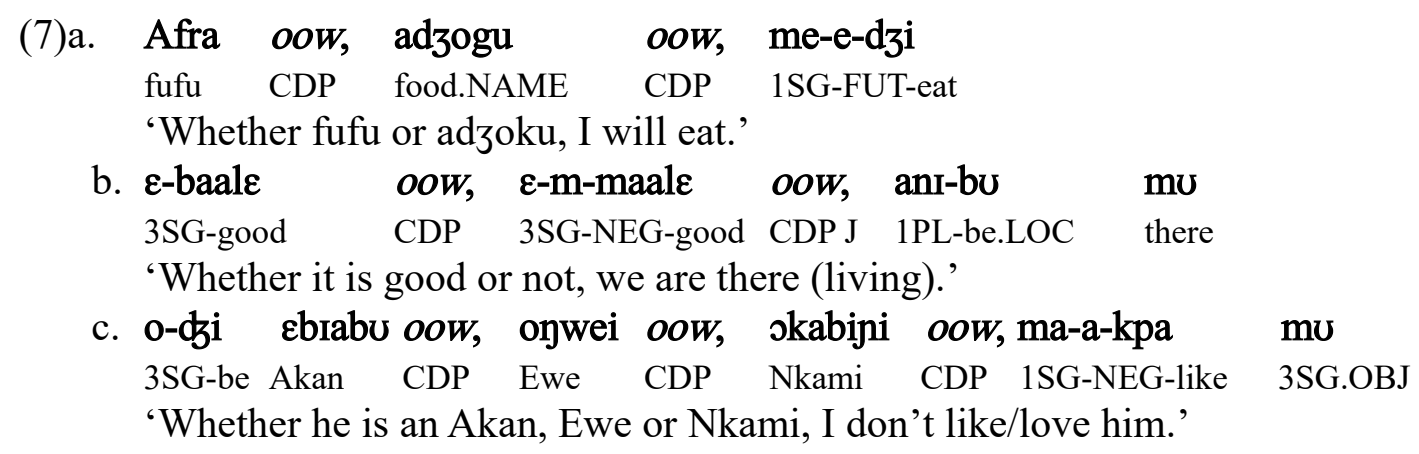

Notice that whereas the coordinators are two in (7a-b) because the coordinands are two, they are three in $(7 \mathrm{c})$ because the coordinands are also three.

Conversely, asyndetic coordination is not as dominant as syndetic coordination in Nkami. It is generally employed for stylistic purposes; as a result, it usually occurs in pithy expressions and narratives, as exemplified in (8a-b) and (8c) respectively.

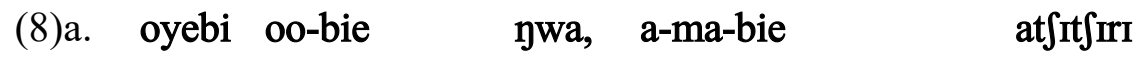

child 3SG.HAB-break snail 3SG-NEG.HAB-break tortoise

'The child breaks (the shell of) a snail, (but) she does not break (that of) a tortoise.'

b. эo-kpa

mmirise asũ, kpa npebi asũ

3SG.HAB-like

adults matter like

children matter

'He likes both adults and children.'

c. feesi nI kotoks bu mi, mialo be-mum-bu mi

first FOC porcupine be.LOC here now 3PL-NEG-be.LOC here

'Before there were porcupines here, (but) now they are not here.' (nkami_huntingoverview_03:52/55)

Sentences (8a and b) are examples of pithy constructions that are covertly connected. For instance, (8a) has an underlying disjunctive coordinator, mo 'but', linking the two

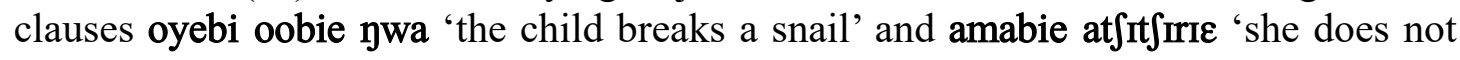
break a tortoise'. Note that oyebi 'child' serves as a metonym of the human being, as the interpretation of the whole sentence in (8a) is analogous to something like 'do not bite off more than you can chew'. 
Here, it must be observed that though the above constructions in (8) do not have overt coordinators linking their component parts, they are not serial verb constructions for the following four reasons, among others. First, unlike SVCs in Nkami (cf. Asante 2016a), the component parts of asyndetic coordination are signalled by intonation breaks, as indicated in writing by the commas in (8). Secondly, in SVCs negation is always marked once on the first verb although its scope covers the entire SVC, as (9) illustrates.

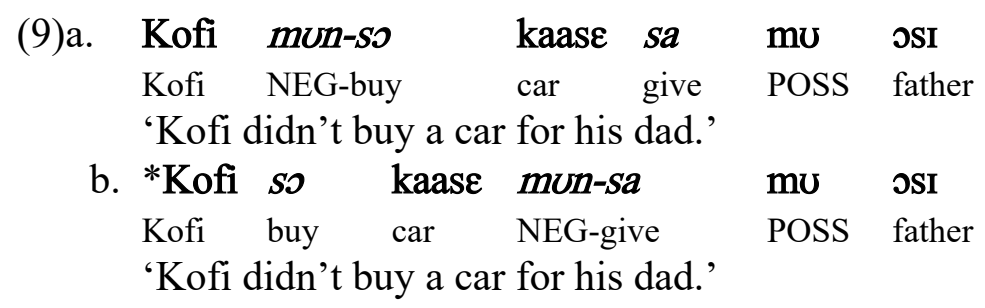

Whereas (9a) is admissible because the negative morpheme, mon-, is prefixed to the first verb, so 'buy', (9b) is infelicitous because mun- occurs on the second verb. However, observe that because the constructions in $(8 \mathrm{a}, \mathrm{c})$ are examples of coordination via covert strategy, the negative morphemes can be attached to the verbs in the second part of the constructions. Thirdly, unlike SVCs where subject marking is typically represented only once on/before the first verb, in asyndetic coordination each of the component parts may have overt subject markings (whether shared or not), as shown in $(8 \mathrm{a}, \mathrm{c})$. Lastly, observe that although it is possible for an asyndetic coordination to have two contrasting temporal adverbs, as shown in (8c), where both feesi 'first/before' and mrals 'now' occur in the same construction having scope over the first and second conjuncts respectively, it is never the case in SVCs. Thus, an entire SVC may have only one temporal adverb, which occurs at either sentence-initial or final positions, with semantic effect over the entire construction. This is illustrated as follows:

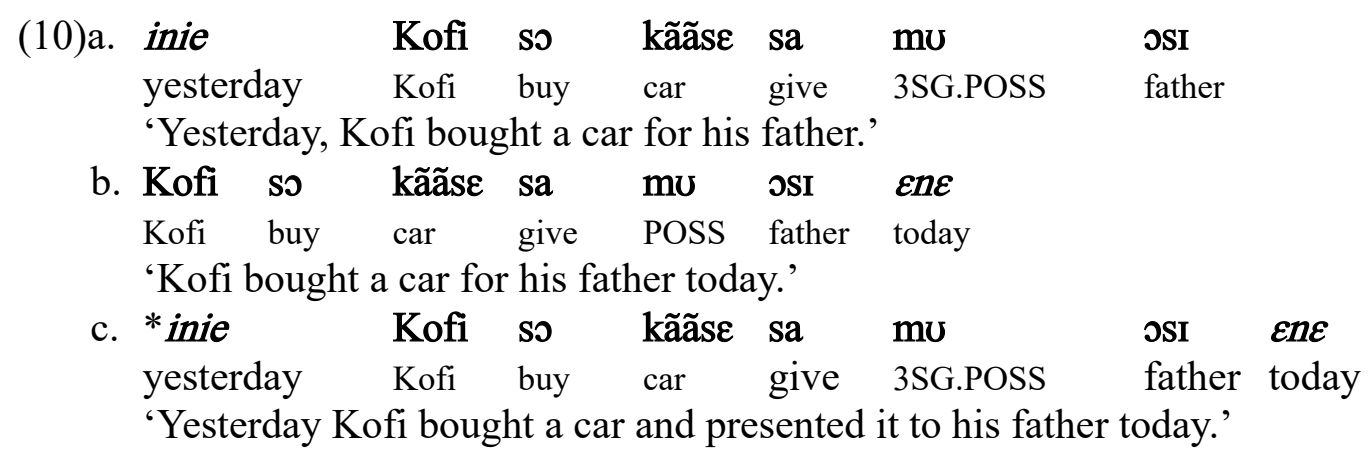

Thus, whereas the SVCs in (10a-b) are acceptable because they have only one temporal adverb, (10c) is unacceptable because both parts have distinct temporal adverbs, inie 'yesterday' and $\varepsilon \boldsymbol{\varepsilon} \varepsilon$ 'today'. 


\section{Linguistic Properties of the Coordinators}

This section examines some linguistic properties of the coordinators with emphasis on morpho-phonological properties. ${ }^{5}$ As we may have noticed above, Nkami has preference for monosyllabic coordinators. Apart from moosu and, to some extent, oow... oow 'whether ... or', all the other coordinators, na 'and', ni 'and', bec/be 'or' and mo 'but', may be considered as monosyllabics. The second thing worthy of note is that the majority of the coordinators have an initial nasal consonant. This appears to be common among Tano-Kwa languages. For instance, Akan also has nanso/nso 'but', anaa 'or', na 'and' and nI (ne in orthography) 'and' (cf. Frimpong 2007). Note the similarity between Akan's conjunctive coordinators, na and nI, and their counterparts, na and nI, in Nkami. However, while Akan employs ni to conjoin phrases and na for clauses, Nkami does the reverse, as we observe in (11-12).

(11) Nkami
a. Kofi na Ama ba mI
Kofi and Ama come here
'Kofi and Ama came here.'
b. Kofi ba mI nI anI-yo
Kofi come here and 1PL-go
'Kofi came here and we went.'

(12) Akan
a. Kofi nI Ama ba-a ha
Kofi and Ama come-PST here
'Kofi and Ama came here.'
b. Kofi ba-a ha na ye-ko-e
Kofi come.PST here and 1PL-go-PST
'Kofi came here and we went.'

The adversative coordinator, mo 'but', appears to be a shortened form of mossu 'but' Synchronically, both exist to perform the same function, as (13) exemplifies.

$\begin{array}{llllll}\text { Kofi } & \text { kpa } & \text { mi } & \text { mo/moss } & \text { ma-a-kpa } & \text { mu } \\ \text { Kofi } & \text { like } & \text { 1SG.OBJ } & \text { but } & \text { 1SG-NEG-like } & \text { 3SG.OBJ } \\ \text { 'Kofi likes me but I don't like him.' } & \end{array}$

This notwithstanding, there seems to be a slight semantic difference between the two forms. It appears that mossu is more emphatic than mo. So, all things being equal, it is more likely for a speaker to select mossu, rather than mo, in (13) if her dislike for Kofi

\footnotetext{
${ }^{5}$ See Section 4 for some more syntactic properties of the coordinators.
} 
is relatively high, and vice versa, if her dislike for him is relatively low. As we shall see in Section 6, almost all the coordinators have some other functions, and are traceable to lexical or less grammatical forms in the language.

Haspelmath (2004: 27) observes that generally 'and' words are shorter (and rarely longer) than 'or' words, as the following data show. ${ }^{6}$

$\begin{array}{lll} & \text { 'and' } & \text { 'or' } \\ \text { German } & \text { und } & \text { oder } \\ \text { Russian } & \mathrm{i} & \text { ili } \\ \text { Hausa } & \text { da } & \text { koo } \\ \text { Iraqw } & \text { nee } & \text { laqaa } \\ \text { Persian } & \text { =ò } & \text { ya... ya... } \\ \text { Lavukaleve } & \text { o } & \text { ve } \\ \text { Dargi } & \text {...-ra ...-ra } & \text { ya(-ra)... ya(-ra)... }\end{array}$

True to Haspelmath's (2004) observation, Nkami seems to conform to this tendency as the 'and' coordinators, nr and na, are shorter than the 'or' word, beq. Again, Nkami conforms to Ohori's (2004) observation that whereas conjunctive coordination often differentiates between NP coordinands and clausal coordinands, disjunction less often does so. Thus, whereas Nkami employs two distinct coordinators, na 'and' nI, for phrasal and clausal conjunction respectively, no such distinction is observed in disjunction, as the language has only one disjunctive coordinator, beع.

Like other functional words in the language, the coordinators are rarely the target for English-Nkami code-mixing. However, based on native speakers' hunch, the adversative coordinator, mossu/mo, stands the greatest chance of being replaced/switched with the English counterpart 'but'. For instance, they contend that while (15d) may be acceptable by Nkami-English bilingual speakers, all the others cannot be admissible.

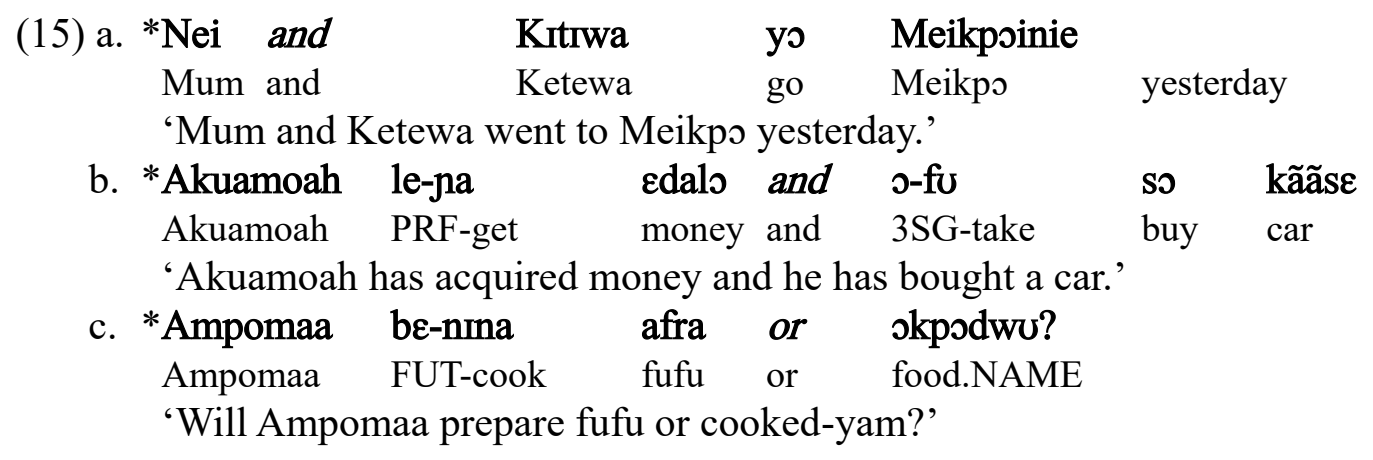

\footnotetext{
${ }^{6}$ It has been observed that a possible reason for this trend is that the conjunctive coordinators are more prominent in discourse than their counterparts for adversative and disjunctive coordination (cf. Haspelmath 2004, Ohori 2004).
} 


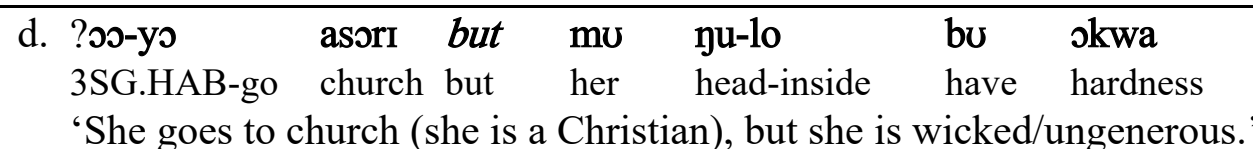

This phenomenon is also consistent with Matras' (1998) observation that adversative coordinators are most likely to be borrowed followed by the disjunctive coordinators and then conjunctive coordinators, as schematised in the borrowing hierarchy below (cf. Haspelmath 2004: 27).

(16) Borrowing hierarchy of coordinators 'but' > 'or' > 'and'

\section{Which Syntactic Structures can be Coordinated?}

This section looks at the types of syntactic structures that can be coordinated in Nkami. In different words, does Nkami allow coordination of independent clauses, or phrases, or simple words, or all of the aforementioned? Nkami allows all of the aforementioned categories to be coordinated, but with some restrictions. As we saw before, like other African languages (Welmers 1973), Nkami employs distinct conjunctive coordinators for phrasal and clausal coordination. Consequently, a distinction between phrasal and clausal coordination in Nkami is in order.

\subsection{Phrasal Coordination}

Some linguists (cf. Radford 1988) distinguish between word-level and phraselevel coordination. However, as rightly observed by Dzameshi (1998) for Ewe, since simple words could qualify as full phrases, I do not make such a distinction. Na 'and' is the only coordinator that is solely employed for phrasal coordination in Nkami, and it can only be used to conjoin identical phrases. For instance, whereas it can conjoin the pair of noun phrases in (17a-c), it cannot be used to conjoin a noun phrase and an adjectival phrasal in (17d).

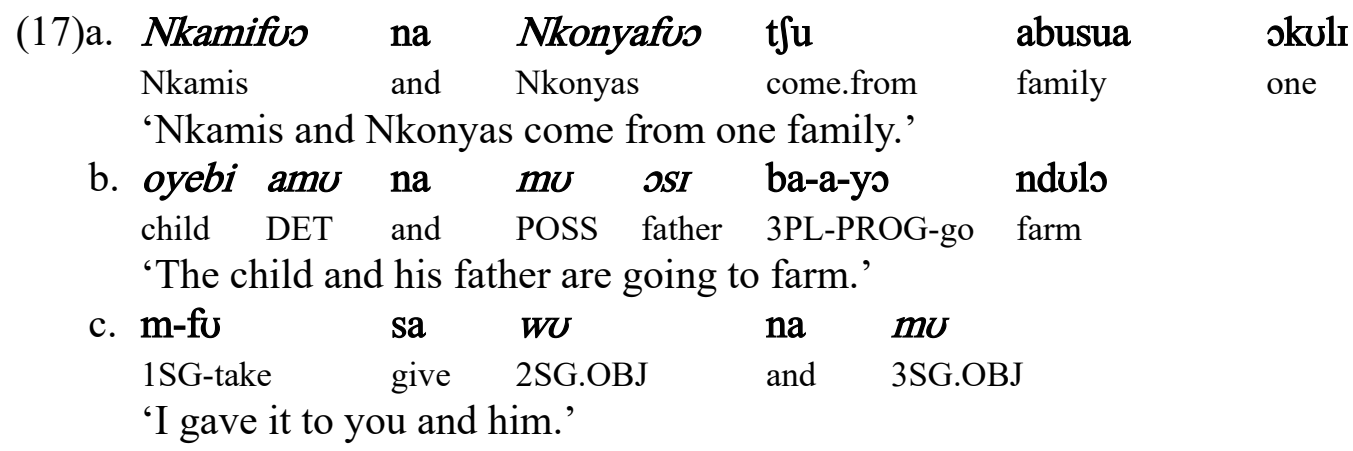




\section{d. *oyebi amu na tuntu ba-a-yo ndulo \\ child DET and black 3PL-PROG-go farm}

'The boy and black (colour) are going to farming.'

Taking (17b) as an example, since oyebi amo 'the boy' and mu osI 'his father' are both noun phrases, the coordinator, na 'and', can be used to link them to form an acceptable phrasal conjunctive coordination in the language. However, because the two phrases in (17d) belong to different categories, i.e. the boy 'noun phrase' and black 'adjectival phrase', they cannot be connected with na. Apart from noun phrases, verbal and adverbial phrases may also be conjoined by na, as in:

(18)a. yo na wU-ye-tfma abia amu su
go and 2SG-DDP-sit chair DET on
'Go and sit on the chair.'
b. o-bo asumi basa.basa na gidigidi
3SG-do work RED.recklessly and quickly
'He did the work very quickly and recklessly (without caution).'

Thus, the conjunctive coordinator connects the verbal phrases, yo 'go' and wu-ye-t $\int$ ina 'you (go) sit', in (18a), and the adverbial phrases, basabasa 'recklessly' and gidigidi 'quickly'. Note, however, that though the majority of informants see (18b) to be acceptable, there are many others too who are either sceptical or see it to be unacceptable. In isolation, adjectival phrases may be conjoined, as shown in (19a). However, when they are used attributively to modify nominals, they fail to be conjoined by the phrasal conjunctive coordinator, na 'and', as (19b) shows.

(19)a. tuntu na timi

black and short

'dark and short'

b. ?wo-o-nu ojni timi na kugo amu?

2SG-PRF-see man short and red DET

'*Have you seen the short and fair-skinned man?'

'?Have you seen the short man and the fair-skinned man?'

As we notice from the italicized part of the English translation in (19b), if the speaker intends to ascribe the attributes, 'short' and 'red/fair', to the same person, as in 'short and fair-skinned man', then, (19b) is infelicitous. However, if the two adjectives refer to two different individuals, as in 'short man' and 'fair-skinned man', then, it may be acceptable. To make the second interpretation more acceptable, the definite article, amu 'the', is placed after the first adjective, timi 'short', as in: 


wo-o-nu onmi timi amu na kugo amu?
2SG-PRF-see man short DET and red DET
'Have you seen the short man and the fair-skinned man?'

As we shall indicate in Section 6, since coordination in Nkami does not allow identical items in parallel structures, the modified NP, onmin 'man', in (20) occurs only once earlier in the sentence before timi 'short'; and so, it is not repeated before the second adjective, kugo 'red'. Consequently, it must be mentioned that the person modified by the adjective, kugo 'red/fair', can only be of the male gender. In different words, (20) cannot index: 'Have you seen the short man and the fair-skinned woman?' Moreover, notice that although both timi 'short' and kugo 'red/fair' provide attribution to the same entity, ojmi 'man', the position of ojmi 'man' is fixed in (20). That is, ojmi 'man' can only occur before the initial adjective, timi 'short', in the initial coordinand. Postposing it to the position immediately before the second adjective, kugo 'red', in (21a), for instance, renders the entire sentence ill-formed.

\begin{tabular}{|c|c|c|c|c|c|c|c|c|}
\hline (21)a. & $\begin{array}{l}\text { *wo-o-yu } \\
\text { 2SG-PRF-see }\end{array}$ & $\varnothing$ & $\begin{array}{l}\text { timi } \\
\text { short }\end{array}$ & $\begin{array}{l}\text { amu } \\
\text { DET }\end{array}$ & $\begin{array}{l}\text { na } \\
\text { and }\end{array}$ & $\begin{array}{l}\text { opInI } \\
\text { man }\end{array}$ & $\begin{array}{l}\text { kugo } \\
\text { red }\end{array}$ & $\begin{array}{l}\text { amu } \\
\text { DET }\end{array}$ \\
\hline & ?'Have you & en $t$ & hort $n$ & in and & he fa & coloure & d man? & \\
\hline b. & $\begin{array}{l}\text { wo-o-yu } \\
\text { 2SG-PRF-see }\end{array}$ & $\varnothing$ & $\begin{array}{l}\text { Timi } \\
\text { short }\end{array}$ & $\begin{array}{l}\varnothing \\
\text { DET }\end{array}$ & $\begin{array}{l}\text { na } \\
\text { and }\end{array}$ & $\begin{array}{l}\text { opmI } \\
\text { man }\end{array}$ & $\begin{array}{l}\text { kugo } \\
\text { red }\end{array}$ & $\begin{array}{l}\text { amu } \\
\text { DET }\end{array}$ \\
\hline
\end{tabular}

However, when the postposition of ojmI 'man' is done concurrently with the omission of the definite article, amu 'the', occurring after timi 'short', as shown in (21b), the sentence would be acceptable, but with a different interpretation. Thus, in (21b) Timi 'Short' is used as a name of a person, and not as an adjective. Hence, Timi 'Short' no longer modifies onmin 'man' in its current usage; only kugo 'red' does. Furthermore, the person by name Timi (or Timitimi) 'Short' does not need to be of the male gender; i.e. Timi could refer to either a man or a woman, unlike in (20) where both timi and kugo 'red/fair' must describe a man.

Still on (19b), if the speaker wants to convey the first reading 'Have you seen the short and fair-skinned man?', where both adjectives, timi 'short' and kugo 'red', modify a single individual, then, what I dub as a 'Serial Adjective Construction (SAC)' is required. SAC here simply refers to any construction that has a sequence of two or more adjectives in contiguity, which modify the same single referent. Thus, the modifying adjectives are not intervened by any overt coordinator(s), as (22) shows. 


\begin{tabular}{lllll}
\hline wo-o-yu & onmi timi & $\varnothing$ & kugo amu? \\
2SG-PRF-see & man short & CONJ red & DET \\
& 'Have you seen the short and fair-skinned man?' \\
'*Have you seen the short man and fair-skinned man?'
\end{tabular}

Put differently, Nkami employs an SAC (or an asyndetic) strategy when the modifiers (adjectives) in a sentence modify the same referent, while a coordinate adjective construction (or a syndetic) strategy is used when the modifiers qualify different referents within the same sentence, as in (20).

Moreover, in some languages such as Akan and English verbs in a series may be conjoined to express separate but conceptually related events, as (23) exemplifies.

$\begin{array}{llll}\text { Akan } & & & \\ \text { ko } & \text { na } & \text { bra } & \text { 'Go and come.' } \\ \text { go } & \text { and } & \text { come } & \end{array}$

However, such combinations are not acceptable in Nkami since the second verb in the series must always be prefixed with a subject pronoun, as (24) indicates.

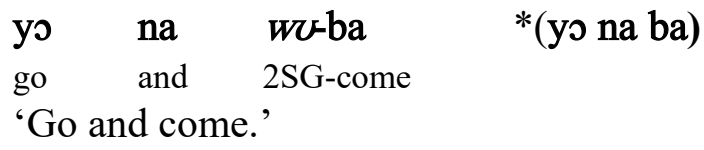

If one decides not to prefix the subject pronoun to the second verb, then, the phrasal conjunctive coordinator, na 'and', must also be elided; in which case, a serial verb construction is derived, as in:

$$
\begin{array}{lll}
\text { yo ba } & \text { 'Go and come.' } \\
\text { go come } &
\end{array}
$$

Though the two imperatives in (24) and (25) are both glossed 'go and come' in English, based on the hunch of native speakers, (25) conveys a more integrated relationship between the actions 'going' and 'coming' than (24). A relatively shorter time is perceived in the realization of the two actions in (25) than in (24). Moreover, (25) may generally be seen as one composite event expressed by two separate verbs, indicating the sub-parts of the entire composite event; while (24) expresses two entirely separate events in a sequence. An evidence to show that (24) expresses two separate events is based on the fact that the second person singular pronoun, wo 'you', could be replaced by other personal pronouns, as (26) illustrates. 


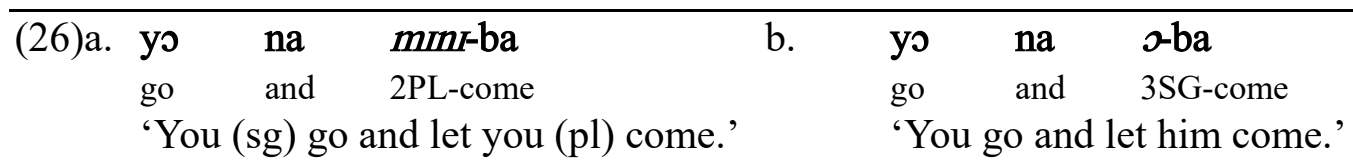

Thus, whereas the addressee is the same as the performer of the sub-events of the SVC in $(25)$, in coordinate verb constructions $(24,26 \mathrm{a}, \mathrm{b})$ the addressee and the performer of the subsequent event may be different. In (26b), for instance, while the addressee and the performer of the first event 'going' is the second person singular subject pronoun, wo 'you', the performer of the second event 'coming' is the third person singular subject pronoun, o- 'he/she'.

Lastly, like many languages such as English, Ga, Nkonya and Akan, in Nkami whenever the conjuncts in phrasal conjunction are more than two, the phrasal conjunctive coordinator, na 'and', appears between the last two conjuncts, as (27) illustrates.

$\begin{array}{llll}\text { So bant5ı, brodzu, } & \text { tojoyi na } & \text { eye } \\ \text { buy cassava plantain } & \text { pepper and } & \text { meat } \\ \text { 'Buy cassava, plantain, } & \text { pepper and meat.' }\end{array}$

Here, Dzameshi (1998) makes an interesting observation about Ewe, another Kwa language, which is worth noting. Unlike Nkami, Ewe has two phrasal conjunctive coordinators, kple and kpakple 'and'. While kple is more commonly used to conjoin relatively fewer list of items, kpakple is employed when the list is exhaustively listed, as (28) exemplifies.

(28) Ewe (Dzameshi 1998: 75)

\begin{tabular}{|c|c|c|c|c|c|}
\hline $\begin{array}{l}\text { a. ame } \\
\text { adults } \\
\text { 'Adu }\end{array}$ & $\begin{array}{l}\text { tsitsi-wo } \\
\text { old-PL } \\
\text { s and child }\end{array}$ & $\begin{array}{l}\text { kple } \\
\text { and }\end{array}$ & $\begin{array}{l}\text { deviwo } \\
\text { children }\end{array}$ & & \\
\hline $\begin{array}{l}\text { b. awu, } \\
\text { shirt }\end{array}$ & $\begin{array}{l}\text { afowui, } \\
\text { socks }\end{array}$ & $\begin{array}{l}\text { afokpa, } \\
\text { shoe }\end{array}$ & $\begin{array}{l}\text { atakpui, } \\
\text { shorts }\end{array}$ & $\begin{array}{l}\text { kpakple } \\
\text { and }\end{array}$ & $\begin{array}{l}\text { atalegbe } \\
\text { trouser }\end{array}$ \\
\hline
\end{tabular}

\subsection{Clausal Coordination}

Nkami has three distinct morphemes that are solely used as clausal coordinators: nI 'and', mo 'but'and mossu 'but'. Payne (1997) observes that though VO languages, like Nkami, have the tendency to position the coordinator between the two clausal coordinands, there are a couple of languages such as Yoruba that place the coordinator after the first element in the second clause. In (29a) and (29b) are sentences from 
English and Yoruba exemplifying the two strategies respectively. ${ }^{7}$

(29)a. [Addo visited grandma] and [she gave him a gift].

b. Yoruba (Payne1997: 338)

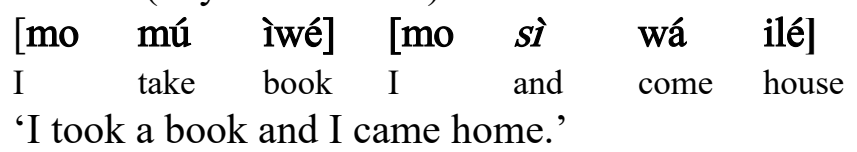

Whereas the English coordinator, and, comes between the two coordinands in (29a), in Yoruba the coordinator, sì 'and', is placed after the subject, mo 'I', of the second coordinand. As indicated earlier, Nkami agrees with the general tendency since the archetypical position of its coordinators is the position between the two coordinands. In what follows is an examination of the distribution of the clausal coordinators in turn. Consider example (30).

Kofi dũ bant $\mathbf{I} \quad \boldsymbol{n I} \quad$ Ama dũ abulo
Kofi plant cassava and Ama plant corn
'Kofi planted cassava and Ama planted corn.'

As indicated before, like most African but unlike most European languages such as English, Nkami has a clausal conjunctive coordinator, nI, which is distinct from the phrasal conjunctive coordinator, na. Ni only occurs between two clauses in coordination, as shown in (31). It neither appears at sentence-initial nor sentence-final positions. In sentence-initial position a different form, nà (with a low tone), is used, as (31) illustrates. ${ }^{8}$

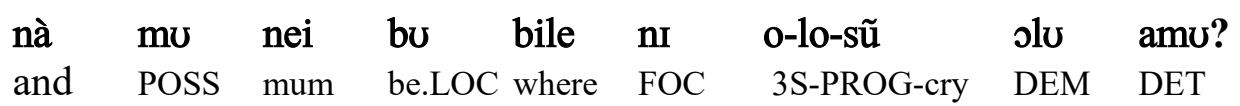
'And where is his mother and he is crying like that? (Where is his mother for him to be crying that much?)'

Generally, when nà is used at the beginning of an utterance, it implies that the interlocutors have a common knowledge of a scene, circumstance or situation which calls for the utterance. A speaker will typically utter (31) when they have sensual access to the child; that is, they may be seeing and/or hearing the child cry. Nà is usually used in interrogative sentences, as in (31). In some instances too, it may also be used by a

\footnotetext{
${ }^{7}$ See Haspelmath $(2004,2007)$ also for a cross-linguistic typological discussion on possible syntactic positions of coordinators.

${ }^{8}$ Akan has an identical form with an identical function(s). It, thus, could be a possible loan from Akan to Nkami.
} 
speaker based on an implicature derived from a preceding proposition(s), especially in narratives. In (32a) is one of such uses employed by obirise Kimpo, a hunting consultant, in the middle of a narration about the role dogs play during hunting; while (32b) sought to know from him if there were elephants in Nkami at a particular point in time.

$\begin{array}{rllllllll}\text { (32)a. } & \text { nà } & \text { m-kpli } & \text { fã } & \text { lo } & \text { amu } & \text { ke } & \text { e-dzi } & \text { Esa } \\ \text { and } & \text { PL-dog } & \text { part } & \text { inside } & \text { DET } & \text { as.for } & \text { 3SG.INANM-be grass } \\ \text { su } & \text { titiriw... } & & & & & & \\ \text { on } & \text { mainly } & & & & & & \end{array}$

'And as for dogs (-hunting), it is mainly on the desert... (that they are used).' (Nkami_hunting overview 03:00-03:03)

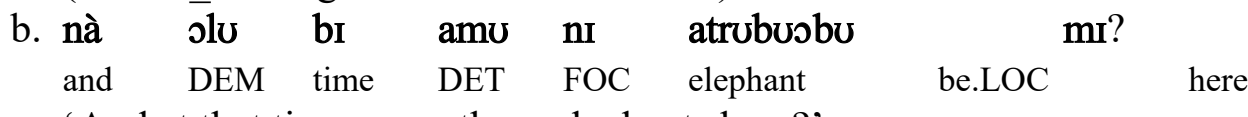
'And at that time, were there elephants here?'

These syntactic observations made about $\mathrm{ni} / \mathrm{nà} \mathrm{can} \mathrm{largely} \mathrm{be} \mathrm{made} \mathrm{about} \mathbf{m o / m o s s u}$

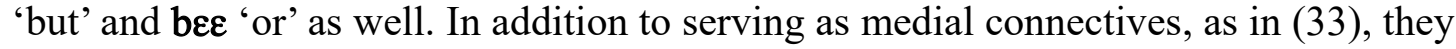
may also be used at sentence-initial position when the participants have a common knowledge about a situation, or when an implicature is derived from preceding proposition(s), as (34a) and (34b) show.

(33) Prototypical position of mo/mossu 'but' and bec 'or'

$\begin{array}{lllll}\text { a. mI } & \text { oSI bu } \text { edalo bebiree } & \text { mo/moss } \\ \text { 1SG.POSS } & \text { dad have money many } & \text { but } \\ \text { o-mun-fo } & \text { anI-yo sukuu } & & \\ \text { 3SG-NEG-take } & \text { 1PL-go school } & & \\ \text { 'My dad has a } & \text { lot of money but he did not take us to school, }\end{array}$

'My dad has a lot of money but he did not take us to school.'

b. wu-be-ba mI bec wu-be-yo mu?

2SG-FUT-come here or 2SG-FUT-go there

'Will you come here or (you will) go there?'

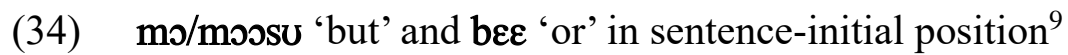

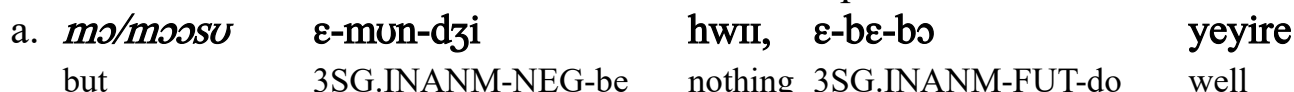

'But it is nothing (all the same, don't worry), it shall be well.'

\footnotetext{
${ }^{9}$ Normally, the front high vowel, /I/, is inserted at word-initial position before the bilabial nasal consonant of mo and mossu, becoming [Imo] and [Imossu] respectively, when they are used in sentence-initial position.
} 

b. beE wo-o-lo?
or 2SG-PROG-be.sick
'Or are you sick?'

Furthermore, only bec 'or' can occur at sentence-final position, as shown in (35). The semantic implication of this usage is discussed in the next section.

$\begin{array}{llllll}\text { wu-be-dzi } & \text { ya } & \text { yo } & \text { owi su } & \text { sec? } \\ \text { 2SG-FUT-be first go sun on or } & \text { go } \\ \text { 'Will you first go to toilet or... } & \text { (go and bath)?' }\end{array}$

Regarding the correlative disjunctive particle, oow... oow 'whether... or', it can be used to connect both phrases and clauses, unlike the other coordinators, as (36a) and (36b) illustrate accordingly.

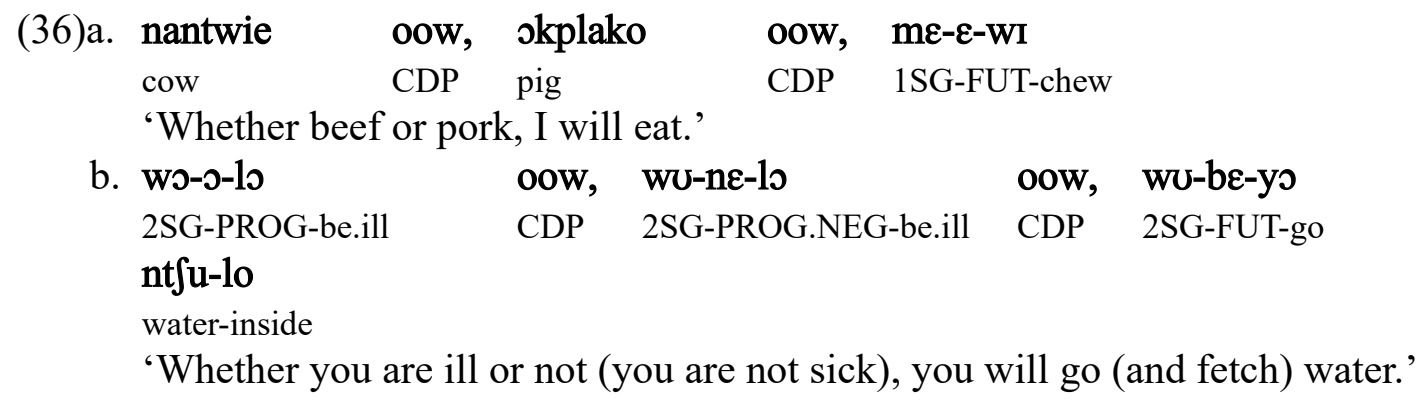

Moreover, unlike the other coordinators, however, the position of the correlative disjunctive coordinator in both phrasal and clausal coordination is fixed: it always follows each of the coordinands in coordination, which it forms a phonological word with.

\section{Semantics and Diachronic Lines of the Coordinators}

Apart from the syntactic function of conjoining clauses and/or phrases, the coordinators play an important semantic role of characterizing the relationships between the coordinands in coordination. Coordination in Nkami, like in many languages, may be rubricised into three main categories: Conjunctive, Disjunctive and Adversative coordination, based on the semantic effect of coordinators upon their coordinands. Let us look at them in turn.

\subsection{Conjunctive Coordination}

Conjunctive coordination (also conjunction or 'and' coordination) in Nkami generally conveys the notion of inclusiveness or supplementation. Often, the expression 
in the second coordinand is seen as an addition to the one in the first coordinand. Two coordinators, na and nu, are respectively used for phrasal and clausal conjunctive coordination in Nkami. Let us see na before nI.

\begin{tabular}{|c|c|c|c|c|}
\hline Amankwa-bu & & na & Adeemera-bu & be-dzi Nkami-fus \\
\hline NAME-IDENT & & and & NAME-IDENT & 3PL-be Nkami-IDENT \\
\hline \multicolumn{5}{|c|}{ 'The people of Amankwa and Adecmera are Nkamis.' } \\
\hline Kofi na & Ama & be-yə & ndulo & \\
\hline Kofi & Ama & 3PL-go & farm & \\
\hline
\end{tabular}

As we observe in (37a), the use of na connotes the idea of inclusion, where people of two different towns, Amankwa and Adeemera, are put into one identical ethnic group, Nkamifos 'Nkamis'. Similarly, the two personal names, Kofi and Ama, are linked together with na in (37b), as either performing the event 'going to farm' collectively (and/or at the same time) or separately (and/or at different times). In different words, the sentence in (37b) necessarily does not have a collective or together-interpretation (cf. Stassen 2000); a together-interpretation is only one of its potential interpretations. Secondly, neither of the two participants, Kofi and Ama, in the construction is backgrounded and that both participants have equal 'structural rank' (cf. Stassen 2000). Furthermore, the two NPs in coordination in Nkami are typically subject to the Coordinate Structure Constraint, which forbids NP-extraction from such constructions (cf. Ross 1967, Stassen 2000). For instance, a coordinand of the coordinate NP in (37b) cannot be extracted for ex-situ focus, as (38) illustrates.

*Kofi ni na Ama be-yo $\quad$ ndulo (amu)
Kofi FOC and Ama $\quad$ 3PL-go
'KOFI (not John, for instance) and Ama went to farm.'

Thus, the extraction of Kofi, a coordinand of the coordinate NP, for focus in (38) results in an ungrammatical sentence. ${ }^{10}$ Besides being used as a phrasal conjunctive coordinator, na may be extended to give 'comitative' interpretation. Thus, speakers will give you the same sentence in (37b) when asked to provide the equivalent of 'Kofi will go to school with Ama', although given (37b) in isolation without any context, no speaker will provide the comitative 'Kofi with Ama' rather than a conjunctive 'Kofi and Ama' interpretation. Thus, it appears that, synchronically, Nkami speakers have no formal means for coding comitative meaning (i.e., accompaniment); they substitute the

${ }^{10}$ This is, however, admissible in some languages such as Akan, as (1) illustrates.

$\begin{array}{lllllll}\text { (1) Kofi } & \text { na } & \text { ne } & \text { Ama } & \text { ko-0 } & \text { afuo }=\mathbf{m} & \text { no } \\ \text { Kofi } & \text { FOC } & \text { and } & \text { Ama go-PST } & \text { farm=inside } & \text { FOC } \\ \text { 'KOFI (not John, for instance) and Ama went to farm.' } & \end{array}$


ordinary coordinate phrase when requested to translate a comitative phrase such as 'Kofi with Ama'. This position is at variance with the popular position that comitative markers typically perform the additional function of a conjunctive coordinator, and that the former usually develops into the later, especially in African languages (cf. Stassen 2000, Haspelmath 2004, 2007).

In the case of the clausal conjunctive coordinator, nI, it links two clauses whose events are performed by the same or different entities. For instance, in (39a) two distinct persons, Kofi and mi [m-] 'I', respectively perform the events of 'giving money' and 'buying a book'. On the other hand, there is subject sharing in (39b), as the same person, mI 'I', carries out both events of 'selling alcohol' and 'selling charcoal'.

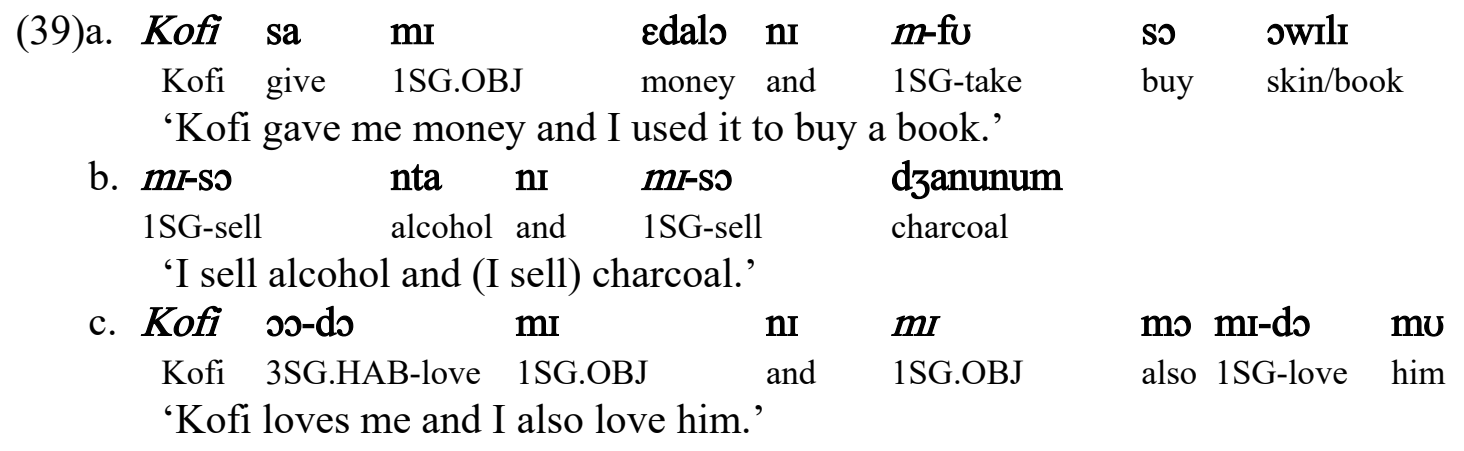

Note that the events carried out, or the state of affairs involved in the two propositions, can be performed simultaneously or at different times. For instance, in (39a) there is a general understanding that the event in the first clause 'giving money' occurs prior to the event in the second clause 'buying a book'. However, in (39c) where the emotive verb, do 'love', is used in both propositions, it is generally understood that the situation in both clauses happens concurrently. Just like in many other languages, the use of the conjunctive coordinator in Nkami may generate an interpropositional (logical) relation of 'conjunction' (cf. Payne 1997, Haspelmath 2007), between the two conjoined propositions. A coordinate construction in Nkami is true iff (if and only if) both propositions in coordination are true. So, for instance, (39c) can only be true if it is true that 'Kofi loves me', and 'I also love him'. Thus, (39c) is false if either of the propositions is false.

Apart from functioning as a clausal conjunctive coordinator, $\mathrm{nI}$ also functions as a relative marker, a focus marker and a proximal predicative demonstrative (PPD) in verbless clauses. Consider the following sentences showing the various indexes of $\mathrm{nI}$.

(40) a. NI as a clausal conjunctive coordinator

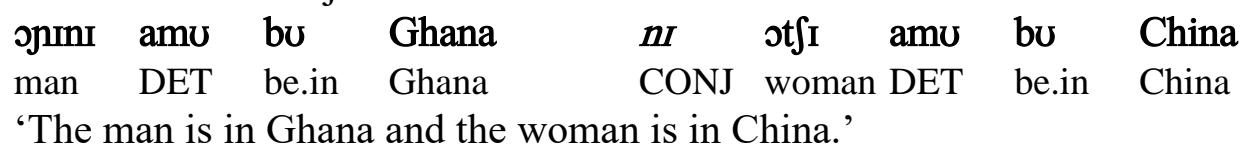


b. Ni as a relative marker

$\begin{array}{lllllll}\text { onmini } & \boldsymbol{n} \boldsymbol{I} & \text { [wu-nu } & \text { mu }] & \text { amu } & \text { bu } & \text { China } \\ \text { man } & \text { REL } & \text { 2SG.SUBJ-see } & \text { 3SG.OBJ } & \text { REL } & \text { be.in } & \text { China }\end{array}$

'The/that man you saw is in China.'

c. Ni as a focus marker

$\begin{array}{lllll}\text { onmini } & \boldsymbol{n} \boldsymbol{I} & \text { wo-nu } & \text { mu } & \text { amu }\end{array}$

man FOC 2SG-see 3SG.OBJ FOC

'It is a man you saw (not a woman).'

d. Ni as a PPD

$\begin{array}{lll}\text { ojini } & \text { amu } & \boldsymbol{n} \boldsymbol{I} \\ \text { man } & \text { DET } & \text { PPD }\end{array}$

'This is the man.'

e. Nu as a DPD

$\begin{array}{lll}\text { oJni amu } & \text { nu } \\ \text { man DET } & \text { DPD } \\ \text { 'That is the man.' } & \end{array}$

(Asante and Ma 2016: 53-54)

Thus, $\mathrm{n}$ I functions as a clausal conjunctive coordinator in (40a), a relative marker in (40b), a focus marker in (40c) and a proximal predicative demonstrative (PPD) in (40d). And here, the explanation offered by Asante and Ma (2016: 53-55) for establishing the diachronic source of the relative marker in Nkami goes for the conjunctive coordinator as well; thus, it may be prudent to suggest that the clausal conjunctive coordinator, as well as the relative and focus markers, diachronically derived from the proximal predicative demonstrative. That is, judging from the four distinct functions of $\mathbf{n r}$ in (40a$\mathrm{d}$ ), one may not be far from right to contend that the reference of $\mathrm{nr}$ is more abstract and less grammatical when employed as a clausal conjunctive coordinator, a relative marker and a focus marker in (40a-c), than its reference in (40d) as a proximal predicative demonstrative. Thus, the first three functions of $\mathrm{nI}$ are similar in the sense that, at the underlying level, it appears to be used as a 'boundary/introductory linker'. However, as a proximal predicative demonstrative, $\mathbf{n} \mathbf{r}$ is used in opposition to nu in verbless clauses (40e) to express the deictic reference of entities. Thus, one can use nI to designate the location of entities in the real world when it functions as a proximal predicative demonstrative, as (40d) exemplifies. However, when $\mathbf{n}$ functions as a boundary linker, it is not deictic, and hence, cannot be used to designate the location of entities in the real world as it does in (40d). Moreover, whereas nI contrasts nu when used as a demonstrative, it is not contrastive as a 'boundary/introductory linker'. In other words, it will not be admissible to substitute nu with nu in (40a-c) to express deictic contrast. In sum, looking at the four distinct functions of nI, clausal conjunctive coordinator, relative marker, focus marker and proximal predicative demonstrative, it may be right to suggest that the first three functions derived from the proximal predicative demonstrative as a boundary/introductory linker before specializing into their 
respective functions, as (41) schematises.

$(41)$

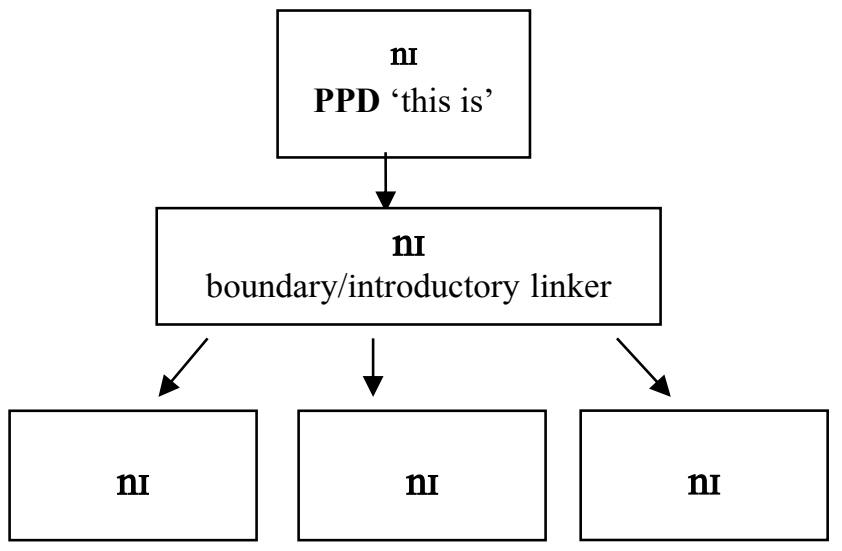

Finally, it may be necessary to note that Nkami is not the only known language whose conjunctive coordinator performs such functions. For instance, Stassen (2000) illustrates cases in some languages where the NP-coordinator seems to be a specialization of the function of a general focus-marking particle, as (41-42) exemplify with Manam and Kabyl (Stassen 2000: 17-18):

(41) Manam (Austronesian, Melanesian)
a. moane-be
aine
di-pura
man-and woman 3PL-arrive

'The men and the women arrived.'
b. wabubu-lo-be i-pura
night-at-FOC 3SG-come
'It was at night that he came.'

(42) Kabyl (Afroasiatic, Berber)
a. agerfiou d' oubarer' raven and fox
'the raven and the fox'
b. netsa d' agellid' en temourth agi
3SG FOC king of country this
'It is him who is the king of this country.'

\subsection{Disjunctive Coordination}

Regarding disjunctive coordination (disjunction or 'or' coordination), speakers may use the disjunctive coordinator, bec/be 'or', to state alternative propositions in Nkami. The use of bee in coordination provides options or alternatives to interlocutors. There are two main types of disjunctive coordination in Nkami. The first one provides 
limited options to interlocutors in discourse, as (43) exemplifies.

(43) Limited options

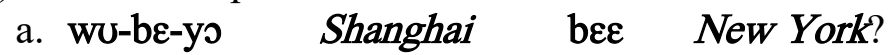
2SG-FUT-go Shanghai or New York
'Will you go to Shanghai or New York?'

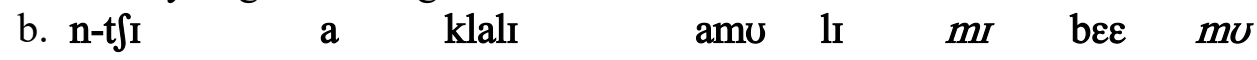
1SG-watch COND grasscutter DET pass here or there
'When I watch (watching), the grasscutter passed here or there.'

In (43a), for instance, there are two available options to the addressee, 'going to Shanghai' or 'going to New York'. The addressee is therefore expected to choose between the two options. When bec is used in this sense, it may generate the logical relation of 'disjunction'. Thus, the truth of either one or both propositions in (43b), for instance, makes the entire coordinate construction true. The construction in (43b) is, however, false if neither of the propositions is true, i.e., if the grasscutter did not pass any of the two locations stated.

Furthermore, bec may be used to provide unlimited alternatives to interlocutors when it occurs at sentence-final position, as (44) illustrates.

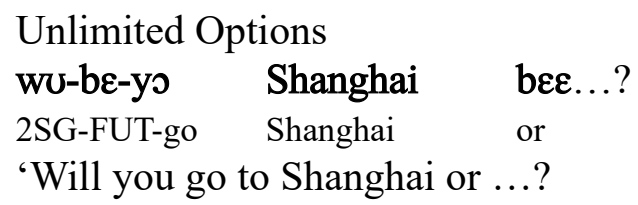

As we observe in (44), the speaker provides unlimited alternatives to the addressee including the one stated, 'Shanghai', and 'any other city in the world', since the proposition in the second coordinand is unspecified. Note, however, that if there is a pause after the first coordinand before the disjunctive coordinator, represented by a comma in writing as (45) illustrates bellow, then, the unlimited interpretation will not hold.

\section{(45) Limited Options}

\begin{tabular}{|c|c|c|}
\hline $\begin{array}{l}\text { wu-be-yo } \\
\text { 2SG-FUT-go }\end{array}$ & $\begin{array}{l}\text { Shanghai, } \\
\text { Shanghai }\end{array}$ & bec...? \\
\hline
\end{tabular}

Thus, as the English translation shows, although the second coordinand of the sentence in (45) is not provided, the addressee has only two available options; that is, 'going to Shanghai' or 'not going to Shanghai', and not 'going to Shanghai' or 'going to any other city', as (44) connotes. 
Like the phrasal conjunctive coordinator, nI, beع is also multi-functional. In addition to being a disjunctive coordinator, it also functions as a preposition, a complementizer, a purposive clause linker, among others. These functions are exemplified in (46) below (Asante 2016b: 244).

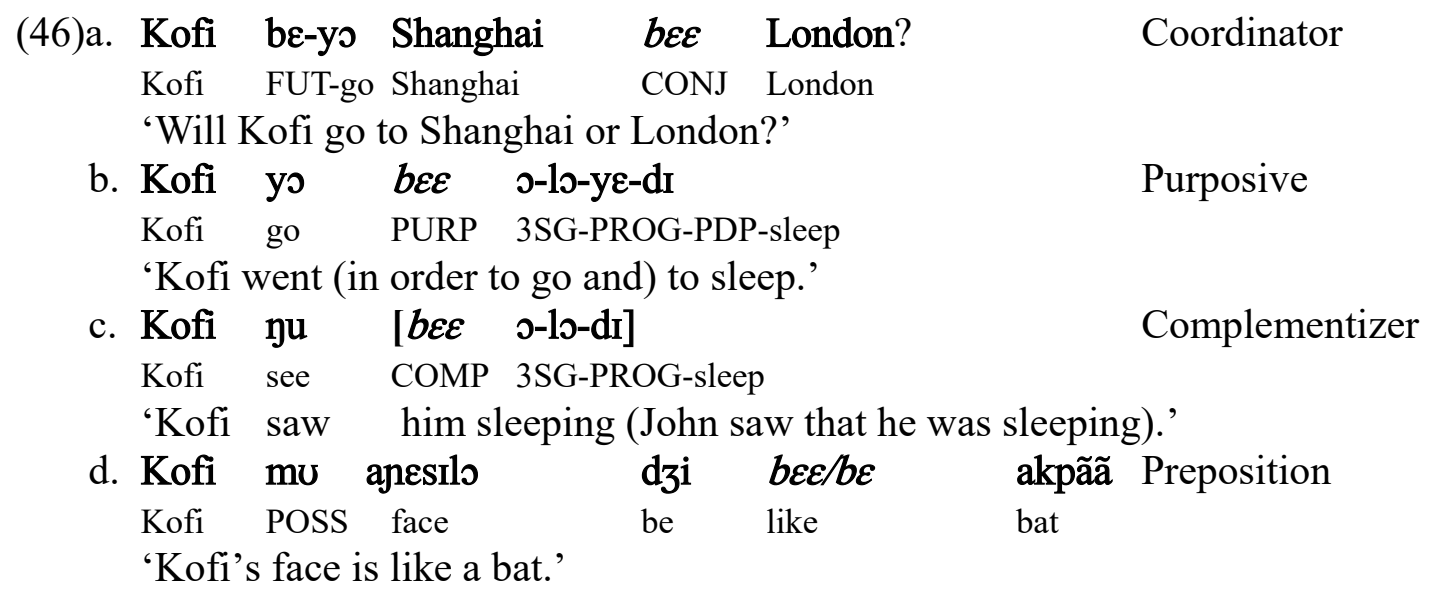

In (46a) bee functions as a disjunctive coordinator, connecting the two conjuncts 'Shanghai' and 'London'. It functions as a complementizer in (46b) by introducing the complement clause, olodi 'he is sleeping'; and it functions as a purposive clause linker, introducing the purpose clause, oloyedr 'he is going to sleep'. Lastly in (46d) it cooccurs with the copula verb, dzi 'be', to perform a function that may be couched as 'prepositional', since it designates the physical similarity between the comparee of comparison 'Kofi's face' and the standard of comparison 'dog'. Following closely from the arguments put forward by Asante (2016b: 244) for establishing the diachronic

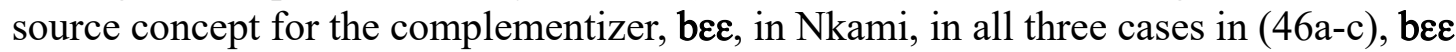
appears to serve as a 'clausal introducer/linker'. Thus, similarly to the argument adduced for the diachronic source of the clausal conjunctive coordinator above, the use

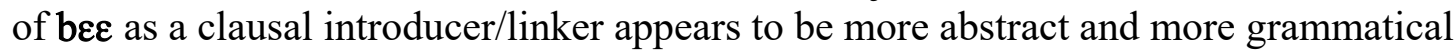
than its use as a preposition (or an inherent complement) of the phrasal verb, dzi bec/be 'be like', in (46d). As a result, it may be appropriate to suggest that the disjunctive coordinator, complementizer and purposive clause linker (PURP) diachronically derived

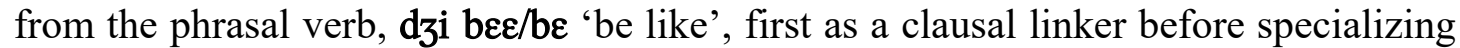
into their respective functions, as (47) schematises. 
(47)

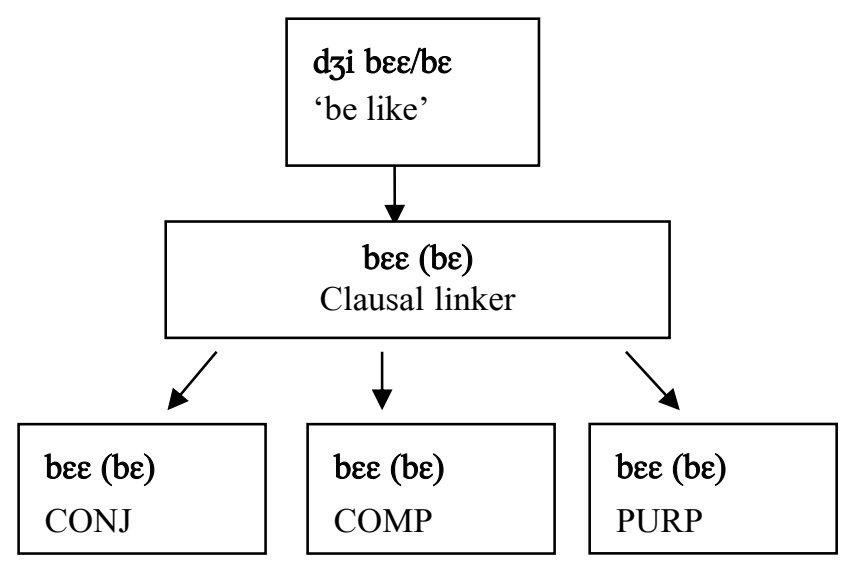

\subsection{Adversative Coordination}

In adversative coordination (or 'but' coordination) there is a seemingly contrast or conflict between the propositions expressed in the first and second coordinands. Nkami employs mossu/mo in adversative coordination, as shown in (48).

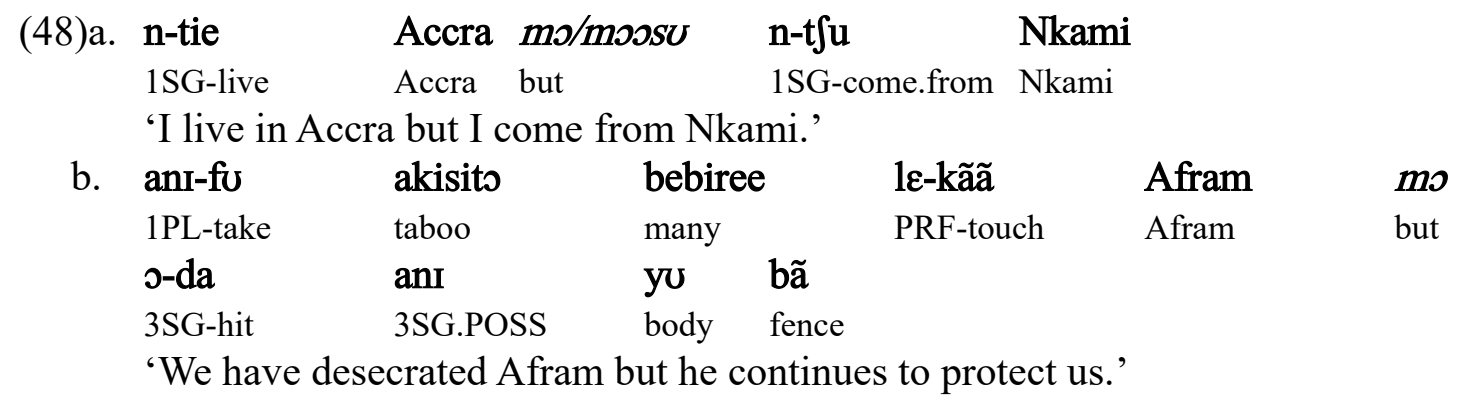

Sentence (48a) conveys the meaning that 'in spite of the fact that I live in Accra (and it appears to you that I am from Accra, I am not), I actually come from Nkami'. A similar interpretation goes for (48b) where one would assume or expect that because of the desecration of Afram (god), he would forsake them, but he does not as he continues to protect them. In both sentences there is a general acceptance of the truths of the first propositions (by the interlocutors), and the second propositions only seek to counteract the derived assumptions (not the truths) from the first propositions by the addressee/hearer.

Unlike the previous coordinators, the adversative coordinator, mo 'but', has fewer functions. It is isomorphic with a morpheme that is similar in function with the English adverbs 'also' and 'too'. As noted above, when mo is used as an adversative coordinator, it indicates contrast, as (49a) further illustrates. On the other hand, there is a sense of inclusiveness when used as an adverb, as (49b) illustrates. 
(49)a. Mo as an adversative coordinator

Kofi os-kpa nta mo Yaw ma-kpa

Kofi 3SG.HAB-like alcohol but Yaw NEG-like

'Kofi likes (drinking) alcohol but Yaw does not like it.'

b. Mo as an adverbial

\begin{tabular}{|c|c|c|c|c|c|c|}
\hline Kofi & oo-kpa & nta, & $\mathrm{nI}$ & Yaw & mo & os-kpa \\
\hline Kofi & 3SG.HAB-like & alcohol & and & Yaw & also & 3SG.HAB-like \\
\hline
\end{tabular}

Moreover, when used as a coordinator, as in (49a), mo immediately precedes the subject of the second clause (here, Yaw); however, as an adverbial, it follows the subject of the second clause and before its predicate. The isomorphism between the inclusive adverb 'also/too' and the adversative coordinator 'but' is not restricted to Nkami. It also shows up in Akan, as (50) exemplifies.

(50) Akan

a. Nso as an adversative coordinator

Kofi pe $\quad$ nsa nso Yaw m-pe
Kofi HAB.like
'Kofcohol but likes alcohol but Yaw does not like it.'
Kofi pe nsa nsoso Yaw m-pe
Kofi HAB.like $\quad$ alcohol but Yaw NEG-like
'Kofi likes alcohol but Yaw does not like it.'

c. Nso as an adverbial

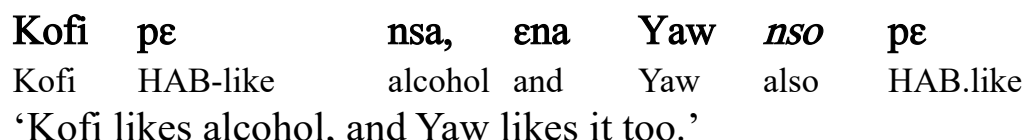

In fact, as we observe in (50b), unlike Nkami, the adversative coordinator, nso 'but', in Akan may engage in a morphological process, namely, reduplication (becoming nsoso), which is common with adverbs in the language. Similarly to the arguments put forward for the two other coordinators above, since mo, as an adverbial, is more lexical and less grammatical than its function as a coordinator, we may assume that the latter derived from the former.

Here, it may be worthy to note that the development of the adverbial 'too, also, as well' into a coordinator is quite pronounced in many of the world's languages. For instance, in her cross-linguistic typological study on the origin of coordinators, Mithun (1988) shows that NP-coordinators grammaticalize from "varied sources including ..., or sentence adverbials with the original meaning 'also, too, as well', or 'furthermore, then, moreover"' (cf. Stassen 2000). The difference, however, is that whereas the adverb 'too, also' has developed into an adversative coordinator in Nkami (and Akan), it developed into conjunctive coordinators in these languages. 


\section{Coordination and Elliptical Rules}

As we have seen in many of the data above, the independent coordinands in coordination may be realized in their full or reduced forms. Observe further below that whereas (51a) has the object NP, afra 'fufu', explicitly stated in both clauses, it is only stated once in the first clause in $(51 \mathrm{~b})$.

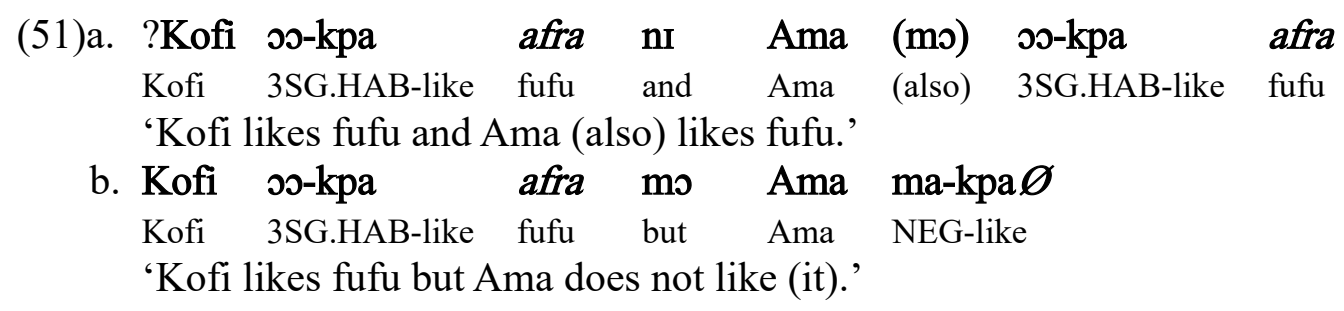

This section, therefore, seeks to explain the mechanisms speakers use to code this and other reduced forms through what has come to be known as 'compression' or 'coordination reduction' rules (cf. Sanders 1977, Schachter 1977, Baker 1978, Payne 1985, Dzameshi 1998, Haspelmath 2007). We will restrict ourselves to the following coordination reduction rules, conjunction reduction, reciprocation and anaphoric substitution, in that order in the following paragraphs.

The rule schema for conjunction reduction requires that for a compound sentence to be reduced to a simple sentence, the various coordinands in the compound sentence should share a 'similar structure'. By 'similar structure', Jacob and Rosenbaum (1968) refer to constituents that are of the same type with identical syntactic function. Thus, the conjunction reduction rule prohibits identical materials in parallel structures (coordinands); so, whenever there is repetition of shared constituents in parallel structures, the repeated materials in the second coordinand are omitted. For instance, both coordinands in (52a) have the phrase yo nduls 'go to farm'. However, since the language does not prefer identical elements in coordination, the second occurrence of the phrase, yo ndulo 'go to farm', is omitted, as (52b) shows.

(52)a. Kofi yo ndulo nI Ama (mo) yo ndvlo
Kofi go farm and Ama also go
'Kofi went to farm and Ama went to farm too.'
b. Kofi na Ama (be)-yo ndulo
Kofi and Ama 3PL-go $\quad$ farm
'Kofi and Ama (they) went to farm.'

When the conjunction reduction rule applies in $(52 \mathrm{~b})$, the subject of the second coordinand is preposed to the position before the main (and only) verb, yo 'go'. The subject that undergoes the movement, Ama, forms an NP compound subject with the 
subject of the first coordinand, Kofi. Evidence to show that the subjects of the two coordinands in (52a), Kofi and Ama, now form a compound subject in (52b) is based on the fact that the main verb may inflect for the third person plural subject pronoun, be- 'they', to co-reference the NP compound subject, Kofi and Ama, in person and number. Also, observe that since the language formally distinguishes between phrasal and clausal conjunctive coordination, the clausal coordinator, nI, in (52a) is replaced with the phrasal coordinator, na, in $(52 b) .{ }^{11}$

Note also that the application of the conjunction reduction rule may bring about ambiguity. In cases where participants (subject arguments) of identical events, as in (53a) where both Kofi and Ama participate in the event of 'going to Kumasi', form a compound subject through the application of the conjunction reduction rule, the resultant sentence may be potentially ambiguous, as (53b) shows.

(53)a. Kofi beyo Kumasi nI Ama (mo) be-yo Kumasi
Kofi FUT-go Kumasi and Ama (also) FUT-go Kumasi
'Kofi will go to Kumasi and Ama will (also) go to Kumasi.'
b. Kofi na Ama be-yo Kumasi
Kofi and Ama FUT-go Kumasi
'Kofi and Ama will go to Kumasi together OR
Kofi and Ama will go to Kumasi separately.'

Thus, the derived sentence in (53b) has two interpretations: 'Kofi and Ama will go to Kumasi together' or 'Kofi will go to Kumasi separately and Ama will go to Kumasi separately'. Contextual knowledge is required to disambiguate them.

Another means by which Nkami achieves syntactic reduction in coordination is through the 'reciprocal formation rule'. The reciprocal formation rule also prohibits repetition of shared constituents in parallel clauses. So, when there is repetition of identical elements in a coordinate construction, the reciprocal pronoun, amu yo 'themselves (each other)', may be introduced to replace the repeated elements(s). This is exemplified in (54).

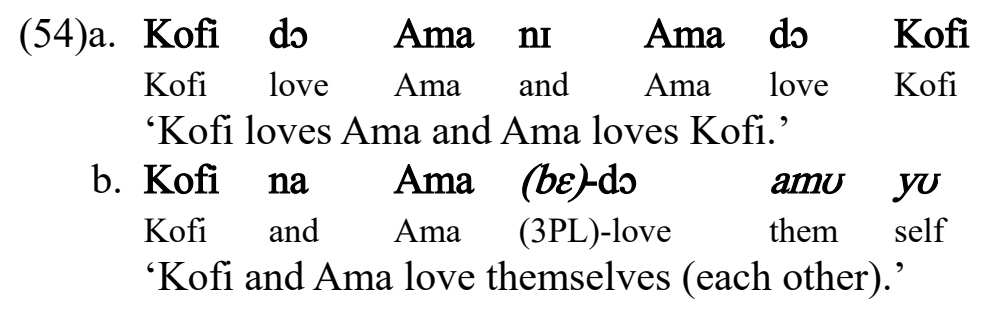

In (55b) the identical constituent, Ama do Kofi 'Ama loves Kofi', is omitted and its position is filled by the reciprocal pronoun amu yo 'themselves (each other)'.

\footnotetext{
${ }^{11}$ See Haspelmath (2007), for instance, for arguments against the conjunction reduction rule.
} 
Remember also that when the subject of the second constituent, Ama, moves leftward to join Kofi to form the compound subject, 'Kofi and Ama', in (55b), the phrasal coordinator, na 'and', substitutes for the clausal coordinator, nr.

Next, like the conjunction reduction and reciprocal formation rules, the anaphoric substitution rule prohibits shared constituents in parallel coordinands. However, instead of omitting one of the shared constituents or introducing the reciprocal pronoun to replace repeated element(s), the anaphoric substitution rule replaces an identical constituent with a special form, which is usually a pronoun or a particle. The anaphoric substitution rule in Nkami is similar to that of English, as both languages replace repeated noun phrases with pronouns. Consider (55) below.

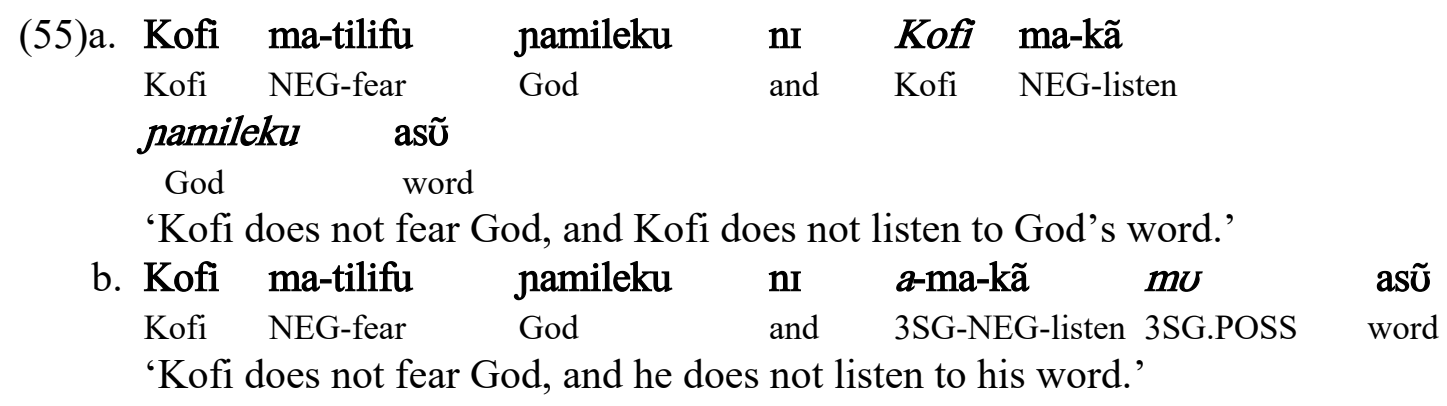

Thus, the repeated NPs, Kofi and namileku 'God', in (55a) are respectively replaced with the anaphoric $3 \mathrm{SG}$ subject pronoun, a-, and the $3 \mathrm{SG}$ possessive pronoun mu 'his'.

\section{Conclusion}

This paper has discussed the syntactic phenomenon of coordination in Nkami, an endangered lesser-known Guang (Niger-Congo, Kwa) language of Ghana, based on synchronic natural data. It has discussed a wide range of issues including coordination strategies in Nkami, number and types of coordinators in Nkami, linguistic properties of the coordinators, allowable types of syntactic structures for coordination, semantic effect(s) of the coordinators on their coordinate structures and the multi-functionality and possible diachronic source concepts of the coordinators. Additionally, some constraints governing Nkami's coordination and the source concepts of the connectives were also discussed. Among other things, it has been observed that Nkami employs both syndetic (overt) and asyndetic (covert) strategies for coordination, though the former is highly restricted occurring chiefly in narratives and pithy sayings. Secondly, just like in the majority of the world's languages (cf. Stassen 2000, Haspelmath 2004, 2007), Nkami employs the monosyndetic NP-coordination strategy by way of a medial connective. Moreover, whereas Nkami employs a Serial Adjective Construction (or an asyndetic) strategy when modifiers (adjectives) in a sentence modify the same referent, a Coordinate Adjective Construction (or a syndetic) strategy is used when the modifiers qualify different referents within the same sentence. The paper also showed four distinguishing features between the two multi-verb construction types, (asyndetic) 
coordination and (linking) SVC, in Nkami with regards to the following parameters: intonation break, negation marking, subject marking, and the number of allowable adverbials belonging to the same sub-semantic type in a sentence. Moreover, we also saw that Nkami has clearly distinct connectives, na and nI, for both phrasal and clausal conjunctive coordination respectively, just like in other African languages (cf. Welmers 1973, Abdoulaye 2004, Lefebvre 2004). Also, almost all the coordinators in Nkami are multifunctional and derivable from more lexical or less grammatical concepts. Further, Nkami shows evidence of the three major semantic types of coordination (Haspelmath 20004, 2007): conjunction (conjunctive conjunction or 'and' coordination), disjunction (disjunctive coordination or 'or' coordination), and adversative coordination ('but' coordination). Other sub-semantic domains such as animacy, conceptual closeness or naturalness, emphasis, inclusion, etc. do not play any significant role(s) in coordination in Nkami (cf. Mithun 1988, Stassen 2000, Wälchli 2003, Haspelmath 2007). Lastly, we also saw that three mechanisms that Nkami speakers employ to achieve syntactic reduction in coordination are conjunction reduction, reciprocation and anaphoric substitution. 


\section{References}

Abdoulaye, Mahamane L. 2004. Comitative, Coordinating, and Inclusory Constructions in Hausa. In M. Haspelmath, ed., Coordinating Constructions. Amsterdam: Benjamins. Pp 165-193.

Aikhenvald, Alexandra Y. \& Robert M. W. Dixon, eds., 2006. Serial Verb Constructions: a Cross-linguistic Typology. Oxford: Oxford University Press.

Asante, Rogers K. 2016a. Nkami Language: Description and Analysis. PhD Dissertation, Tongji University.

Asante, Rogers K. 2016b. Complement Clause Constructions in Nkami. Acta Linguistica Hafniensia 48.2: 219-248, DOI:10.1080/03740463.2016.1242829.

Asante, Rogers K., and Qiuwu Ma. 2016. Relative Clause Constructions in Nkami. Studies in African Linguistics 45.1\&2: 27-59.

Baker, Carl L. 1978. Introduction to Generative-transformational Syntax. New Jersey: Prentice-Hall.

Bamgbose, Ayo. 1973. The Modifying Serial Construction: a Reply. Studies in African Linguistics 4.2: 207-217.

Bamgbose, Ayo. 1982. Issues in the Analysis of Serial Verb Constructions. Journal of West African Languages 12.2: 3-21.

Dik, Simon C. 1968. Coordination: Its Implications for the Theory of General Linguistics. Amsterdam: North Holland.

Dzameshi, A. K. 1998/1989. Structures of Coordination in Ewe. Journal of West African Languages 27.1: 71-31.

Frimpong, Nana K. S. 2007. Conjunctions in Akan. Mphil Thesis, University of Ghana.

Jacops, Roderick A. \& Peter S. Rosenbaum. 1968. English Transformational Grammar. London: Ginn and Co.

Haspelmath, Martin. 2004. Coordinating Constructions: an Overview. In Martin Haspelmath, ed., Coordinating Constructions. Amsterdam: Benjamins. Pp 3-39.

Haspelmath, Martin. 2007. Coordination. In T. Shopen, ed., Language Typology and Syntactic Description. Cambridge: Cambridge University Press. Pp 1-51.

Kibrik, Andrej A. 2004. Coordination in Upper Kuskokwim Athabaskan. In Martin Haspelmath, ed., Coordinating Constructions. Amsterdam: Benjamins. Pp 537553.

Lefebvre Claire. 2004. Coordinating Constructions in Fongbe with Reference to Haitian Creole. In Martin Haspelmath, ed., Coordinating Constructions. Amsterdam: Benjamins. Pp 123-164.

Matras, Yaron. 1998. Utterance Modifiers and Universals of Grammatical Borrowing. Linguistics 36: 281-331.

Mithun, Marianne. 1988. The Grammaticalization of Coordination. In J. Kaiman and S. A. Thompson, eds., Clause Combining in Grammar and Discourse. Amsterdam: Benjamins. Pp 331-359. 
Ohori, Toshio. 2004. Coordination in Mentalese. In Martin Haspelmath, ed., Coordinating Constructions. Amsterdam: Benjamins. Pp 41-66.

Osam, Kweku E. 2003. The Trondheim Lectures: an Introduction to the Structure of Akan, its Verbal and Multiverbal Systems. Legon: Department of Linguistics.

Payne, John R. 1985. Complex Phrases and Complex Sentences. In T. Shopen, ed., Complex Constructions. Cambridge: Cambridge University Press. Pp 3-41.

Payne, T. 1997. Describing Morphosyntax: a Guide for Field Linguists. Cambridge: Cambridge University Press.

Radford, Andrew. 1998. Transformational Grammar: a First Course. Cambridge: Cambridge University Press.

Ross, John R. 1967. Constraints on Variables in Syntax. Bloomington: Indiana University Linguistics Club.

Sanders, Gerald A. 1977. A functional Typology of Elliptical Coordination. In F. R. Eckman, ed., Current Themes in Linguistics: Bilingualism, Experimental Linguistics, and Language Typologies. Washington, DC: Hemisphere. Pp 24170 .

Schachter, Paul. 1977. Constraints on Coordination. Language 53: 86-103.

Sebba, Mark. 1987. The Syntax of Serial Verbs. Amsterdam: Benjamins.

Stassen, Leon. 2000. AND-languages and WITH-languages. Linguistic Typology 4.1: 1-55.

Wälchli, Bernhard. 2003. Co-compounds and Natural coordination. PhD Dissertation, University of Stockholm.

Watson, Richard. 1966. Clause to Sentence Gradations in Pacoh. Lingua 16: 166-168.

Welmers, W. 1973. African Language Structures. Berkeley: University of California Press. 